\title{
Teachers' Perceptions and Needs of CLIL: A Collective Case Study from Turkey
}

\section{OPEN ACCESS}

Manuscript ID:

EDU-2020-09013506

Volume: 9

Issue: 1

Month: December

Year: 2020

P-ISSN: 2320-2653

E-ISSN: 2582-1334

Received: 01.10.2020

Accepted: 05.11.2020

Published: 01.12.2020

Citation:

YAVUZ, Ahmet Cihat, et al. "Teachers' Perceptions and Needs of CLIL: A Collective Case Study from Turkey." Shanlax International Journal of Education, vol. 9, no. 1, 2020, pp. 92-103.

DOI:

https://doi.org/10.34293/ education.v9i1.3506

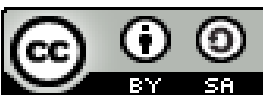

This work is licensed under a Creative Commons Attribution-ShareAlike 4.0 International License

\author{
Ahmet Cihat Yavuz \\ School of Foreign Languages, Bursa Technical University, Bursa, Turkey \\ https://orcid.org/0000-0002-3246-952X
}

\section{Ali Öztüfekçi}

Department of ELT, Bahçeşehir University, Istanbul, Turkey

https://orcid.org/0000-0002-4519-3796

\section{Aybüke Demet Ören}

State High School, Istanbul, Turkey

https://orcid.org/0000-0001-6306-8123

\section{Ayten Kaplan}

Vocational High School, Istanbul, Turkey

https://orcid.org/0000-0001-5500-6790

\section{Çiğdem Yilmaz Uzunkaya}

Sehir University, Istanbul, Turkey

https://orcid.org/0000-0003-1018-2082

\begin{abstract}
Since the 1990s, CLIL has become a popular and well-established educational approach in English Language and Teaching (ELT) and has been cited for its positive learning outcomes. CLIL's rising popularity in ELT is predicated on the necessity of internationalisation and unprecedented population mobility (Nikula, Dalton-Puffer and Llinares, 2013). Another reason why CLIL has attracted scholarly attention is attributed to CLIL's pedagogical practicality. As Coyle (2006) suggests, CLIL can offer "opportunities involving problem-solving, risk-taking, confidence building, communication skills, extending vocabulary, self-expression and spontaneous talk" (p. 7) because it fuses content and language learning with a dual-approach. Such being the case, the aim of this collective case study was to investigate 5 in-service high school EFL teachers' perceptions about and needs of CLIL. In line with this goal, relevant data were collected through 1) reflective essays written by the participants after reading the article about CLIL, which was distributed to them for raising awareness purposes, 2) semi-structured interviews with them after these lessons. This was a purely qualitative study with the aims of gaining an in-depth insight into the topic at hand from the teachers' points of view and creating a venue for their voices to be heard. Data garnered from these tools were carefully scrutinized, and the pattern coding generated three main themes regarding the research questions, namely CLIL's benefits and challenges and teachers' needs.
\end{abstract}

Keywords: CLIL, English language teaching, Internationalisation, Teachers' perceptions, Teachers' needs

\section{Introduction}

Content and Language Integrated Learning (CLIL), focusing on the process and outcome instead of the method, is an approach to foreign language teaching. A language is learned through the content or knowledge that students are supposed to acquire (Richards and Rodgers, 2001). 
Unless a school-wide interdisciplinary contentbased instruction (CBI) or a CLIL-based ELT curriculum is adopted and followed, it is generally the responsibility of language teachers to select the themes, topics and contents and integrate them into the course. In light of this information, determining the needs of CLIL can be administered to both teachers and students, which possibly yields the needs of teacher training, materials and specific information about the methodology. For a successful implementation of CLIL it is essential to provide teachers with the support, materials and training they need. Needs analysis (NA) can be administered through questionnaires, tests, interviews or classroom observation (Ruiz-Garrido and FortanetGómez, 2009). The results of a comprehensive NA reveal teachers' demands and needs to provide them with the proper training and support.

One of the major reasons of CLIL use in foreign language teaching is that it offers students to use the language in a meaningful way which increases the possibility of retention of newly learned knowledge and ultimately acquisition of the target structure/ word etc. It also increases student proficiency of foreign language without taking too much time in the busy curriculum by incorporating English with content of other subjects. Over the last two decades, CLIL has been widely used in Europe in particular, and in recent years it is getting popular in Asian and Latin American contexts as well (Yassin, et al, 2009; Banegas, 2011). However, CLIL seems to be mostly researched from the perspectives of subject-teachers as opposed to English-teachers around the world. Such being the case, while reviewing the literature firstly, studies from the world were scrutinized.

In the study by De Graaff, et al., (2007) three Dutch CLIL secondary schools were observed and an observation tool which had been constructed by the researchers was used to analyze the data. The aim of the study was to observe and make an analysis of an effective CLIL lesson which helps students improve their language skills. Satisfactory evidence was found for the criteria of effective language teaching in the observed CLIL lessons. In some other studies the attitudes of the teachers towards CLIL were examined and results showed that teachers had positive attitudes towards the use of CLIL. Specifically speaking, Dafouz et.al (2007) studied on the reflections of both the students and teachers in the Universidad Complutense de Madrid and the Universidad Politécnica in Spain on CLIL. 70 content teachers and 85 Spanish undergraduate university students were participants in the study, and two different questionnaires were used as data collection instruments. Results showed that both groups have positive attitudes towards CLIL even though the level of eagerness to implement it differs. They stated that they would prefer more interactive classes.

Along with this, teachers stated that they need the support of administration and students stated that even if they are aware of the fact that CLIL is beneficial, they have difficulty in their lessons even in their mother tongue, so in another language it can be an obstacle for them to learn the other subjects. In another study conducted by Infante, Benvenuto, Lastrucci (2009) with 11 Italian primary teachers, interviews and questionnaire were used as data collection instruments. According to some of the results of the study, the attitudes of teachers towards CLIL is positive even though they reported some problems like the scarcity of the materials. They stated that they need training and also to have the chance of meeting other CLIL teachers so as to exchange ideas with other teachers. They also would prefer the schools to connect to the academic world. It was also found out that CLIL helped teachers develop their level of reflection.

Some studies, on the other hand, approached the topic from the needs for materials and teacher training for application of CLIL in schools. RuizGarrido and Fortanet-Gomez (2009) suggested in their descriptive study that in order to diagnose the needs of teacher training and necessary materials in a CLIL programme, NA should be conducted. As by doing a NA in CLIL, both the teachers' and the students' needs can be discovered. By finding out teachers' needs, teacher training courses can be organized accordingly. In his study Mehisto (2012) describes the criteria necessary for developing CLIL materials by starting from the criteria for developing any kind of learning materials. The ten criteria stated in the study for developing quality CLIL materials are; 1) making the learning intentions (language, 
content, learning skills) \& process visible to students, 2) systematically fostering academic language proficiency, 3) fostering learning skills development and learner autonomy, 4) including self, peer and other types of formative assessment, 5) helping create a safe learning environment, 6) fostering cooperative learning, 7) seeking ways of incorporating authentic language and authentic language use, 8) fostering critical thinking, 9) fostering cognitive fluency through scaffolding of a) content, b) language, c) learning skills development helping student to reach well beyond what they could do on their own, 10) helping to make learning meaningful. Not only specific examples of materials but also examples of how to apply the criteria during the production are placed in the study. The article serves as a tool to create CLIL materials. Wolff (2012) sees CLIL as a way to bring about real change into the education system with its potential of innovation in schools. In his descriptive study, Wolff (2012) focuses on teacher training and offers a framework to European teachers using CLIL in their classrooms for professional competence and professional development. In the former, he emphasized the awareness of content and language, competence of methodology, classroom management, CLIL management, evaluation and assessment, etc. In the latter, he focused on three modules of professional development; a) approaching CLIL, b) implementing CLIL, c) consolidating CLIL.

As for the studies conducted within the Turkish context, implementing CLIL in Turkey has not been a new trend, but there has not been much research into the issue of applying CLIL-based activities in the EFL teaching profession and its role has received less attention in Turkey compared to European contexts. Back in 1950s when the first special type of high school (Anatolian High School) for selected high achieving students with more intensive English courses started, the aim was to use foreign languages as the medium of instruction. However, such programmes failed to be successful as teachers lacked the necessary proficiency to teach the subject matters through a second language, that is, they had no training courses nor did they have any kind of education to do so.
In a study conducted in Turkey with 244 ELT student teachers, Bedir (2013) aimed to raise awareness of the participants on CLIL. By doing so, the researcher attempted to find out whether or not the participating ELT student teachers were in favour of the idea of integrating the CLIL based activities into their own practices. In parallel to this, the researcher employed a mixed data collection procedure to be better able to collect more indepth data so as to analyse the perceptions of the respondents regarding the implementation of CLIL. With regard to the results, the research concluded that the vast majority of the participants were not aware of CLIL and had no ideas on the issue. Yet again, most of the participants favored the objectives that CLIL can provide, to wit: the relevant research in Turkey focuses more on CBI (Kiziltan and Ersanl1, 2007; Arslan \& Saka, 2010) than CLIL (Bozdoğan and Karlıdağ, 2013), concentrating on the theme-based model and its implementation. In another study, Kizıltan and Ersanl1 (2007) conducted an experimental study with 87 young learners, 44 in the experimental and 43 in the control group, from a public school to find out the contribution of the theme-based model of content-based Instruction (CBI) to their language development in English. The experimental group were taught basic language skills in English through theme-based CBI for fifteen weeks.

The data were collected through an achievement test. The results indicated that the learners in the experimental group had improved their language skills in English better than those in the control group. The study revealed that CBI is more effective for young learners' language development and the authors suggested that English teachers should use $\mathrm{CBI}$ in their classrooms, pre-service language teachers should be trained to use CBI more effectively, language teachers could work collaboratively with other major teachers in their schools and the textbooks might be designed accordingly. Additionally, Kiraz et al. (2010) investigated the effectiveness of science and technology learning in the foreign language in a study which they conducted with 78 randomly chosen 8 th-grade students, 44 girls and 34 boys, who take science and technology courses in English at private and public schools 
in Northern Cyprus. They utilized "Science and Technology Class Attitude Scale" and "Science and Technology Class Success Scale" to collect data on both students' success and attitudes, and to find out the correlation between them. The findings indicated that, although the students' academic success was low in the successful test, they had a high positive attitude towards the integration of those courses with language learning. Another study which aimed to find out whether CBI was effective on learners' study fields or not from their own perspective, was Oruç (2008). The participants were 40 students aged 17-23 from three different departments of two state universities, and the data were collected through questionnaires. The findings revealed that studying in English or their native language did not affect the perceptions of the learners in terms of success in their field. However, one thing that is worth-mentioning is related to the fact that the vast majority of teachers working in bilingual institutions are not sufficiently equipped with the required knowledge to carry out their professions.

Yet, the study which concurs with what has thus far mentioned is Canbay (2006), in which an NA was conducted to find out which skill, among reading, writing, speaking, listening and translation, has the highest priority for the English medium departments from the point of 128 content area teachers and 13 heads of departments and determining the needs for specific language tasks and activities related to those skills in a state university, in Turkey. The data were collected through questionnaires and interviews and the results indicated that the perception of most important skill varied for the teachers from one department to another; however, the majority of content area teachers thought that receptive skills, particularly reading, is the most important skill for the English-medium departments. The author, therefore, suggested that the academic needs of the learners should be taken into consideration to give a purposeful education through CBI. Moreover, in the context of this study, it was observed that varying requirements of the relevant departments are to be taken into consideration to help students better acquire the knowledge they need to continue with their departmental studies in their respective majors, viz., to help them achieve their desired goal of getting ready, language-wise, for what they would be dealing with in their future endeavors.

\section{Method \\ Aim of the study}

The aim of this collective case qualitative study is to determine the perceptions and investigate the needs of science high school English language teachers about CLIL per se and its implementation in their classes. Based on a case study which integrated article analysis, reflective essays, lesson plan and interviews, the present study further aims to provide the school administration with content and ideas in preparing in-service training programs, which is assumed to raise the effectiveness of such programs because of its utmost pertinence to teachers' needs. In line with this goal, the following questions were addressed in this study:

1. What are the teachers' perceptions of CLIL approach?

2. What are the teachers' needs for CLIL-based lessons?

\section{Setting and Participants}

The study was conducted at the science high school of a k-12 educational institution based in Istanbul, Turkey. The school delivers English as a foreign language from grade 9 to grade 12 via skillsbased textbooks selected at the beginning of the term. Although CLIL has not been adopted as the major approach, course lecturers prepare and implement CLIL lessons after inspiring from the units of the textbooks that include CLIL-adaptable units concerning multiple sciences such as Geography, Physics, Chemistry, Art and so forth. The school also invested in CLIL by designing a special room for CLIL lessons. In this study, three 9th grade and two 10th grade classes were involved. The class size varies within the range of 12-21.

The participant teachers, whose background information is given below, were selected on a voluntary-based selection procedure.

Participant 1, 40, is a BA holder in English Language Teaching and has been teaching English since 2003. So far, she has taught various age groups from kindergarten to high school for 13 years in this institution. She had a great deal of experience 
with CLIL-oriented lessons as required by the ELT curriculum in primary and middle schools from 2010 to 2014. She currently prepares and implements CLIL lessons in high school regularly.

Participant 2, 35, is a BA holder in English Language Teaching, and has been teaching English since 2003. She has teaching experience with only high school students and this is her first year in this institution. She does not have a lot of experience with CLIL-based teaching. It is safe to say that her encounter with this approach started this year. That is why she gets assistance from her colleagues when she needs it.

Participant 3, 31, is also a BA holder in English Language Teaching and has been teaching English since 2009. At the beginning of her career she taught young learners for 3 years, and now she has been teaching high school students for 5 years in this institution. She also did CLIL lessons intensively in her first years with young learners. She regularly prepares CLIL-based lessons in collaboration with such subject teachers as Math, Physics and Biology and actively engages in spreading her implementations with fellow teachers.

Participant 4, 26, is a BA holder in English Language Teaching and has been an active teacher for 4 years. She only had one year of experience with young learners at the very beginning of her professional career. She, as a novice teacher, started integrating CLIL methodology into her lessons in 2016 when she got inspired from her fellow teachers having performed in in-service workshops. She currently teaches English through CLIL in her 9th grades.

Participant 5, 23, is a BA holder in American Language and Literature and an MA in English Language Teaching. Unlike the rest of the participants, she has been through the first year of the professional career and did not naturally do any CLIL-focused lessons before. She has prepared and implemented a couple of CLIL lessons with 9th grade students in cooperation with mentor teachers and volunteer subject teachers.

\section{Data Collection Tools}

Two data collection tools were made use of. Firstly, the participants were asked to write reflective essays concerning their opinions and feelings about implementing CLIL into their teaching. This tool was selected to trigger consciousness about CLIL through an article explore the participants' existing perceptions of CLIL. Later the participants conducted a CLIL based lesson in their classes using their textbook's CLIL unit (Soars and Soars, 2009).

Interviews allow researchers to understand the participants' feelings, thoughts and intentions as a whole which would be overlooked if only observed behaviors and events were taken into consideration (Patton, 1987). Therefore, as the second tool, a semistructured interview was used as the instrument of this study, and five teachers were interviewed oneon-one in the English department office of the school over a week. The interviews lasted for approximately 30 minutes in length, recorded with consent from the participants and later transcribed by the researchers. They began with biographical opening questions followed by the interview questions. The aim of these interviews was to understand what the teachers' perceptions and needs were when it comes to using CLIL in their contexts.

\section{Data Analysis}

After getting consent from the administration of the school, the researchers started their study by choosing the participants and explaining to them the steps of the study. The study intervened with the routine instructions of the participating instructors with the implementation of a CLIL lesson. The instructors were initially given an article (Xanthou, 2010) to read, which contains information about the definition and implementation of CLIL, its contribution to language learning in terms of vocabulary extension by association through activating prior knowledge, repeated exposure and contextualization, with the aim of familiarizing them with the concept of CLIL or improving their insight about CLIL and its effects. Secondly, the instructors were asked to write reflective essays expressing their ideas and thoughts about involving CLIL in their instruction of English and their views on the advantages and disadvantages of implementing CLIL in their classrooms. As the third step, the instructor was provided with a CLIL lesson plan to analyze and apply in their classrooms. Following the 
implementation of the CLIL lesson, they were finally interviewed in-depth about their views on their experience with the CLIL lesson and their views on CLIL-based instruction, its benefits and challenges in general. The qualitative data collected using the reflective essays and interviews were analyzed indepth and interpreted by the researchers.

As qualitative studies enable a deeper understanding of the participants by bringing their voice to the study, they are the most effective way to investigate the participants' attitudes and outlooks on any given topic (Flick, 2009). Both the qualitative data collected from the reflective essays and the data collected using the interviews which were transcribed comprehensively and carefully analyzed using pattern coding as suggested by Miles and Huberman (1994). The researchers analyzed raw data out of each instrument inductively, coded them against recurring themes and read and reread the responses from the transcripts with the aim of making sense of the data and ensuring the codes and themes in the responses. The emerging codes and major themes were rechecked iteratively to make interpretations. At the end of the study, the findings were shared with each of the participants for authenticity, and all the participants confirmed the originality of the findings in person.

\section{Findings}

\section{Reflective Essays}

In the present study two qualitative data collection instruments, namely reflective journals and interview questions were employed to get most in-depth data that reveal congruence with the aim of the study. To this specific end, the participants put their perceptions, attitudes and feelings into the words, which yielded comprehensive results about their views and needs. The following section reports the recurring themes in their reflective essays:

\section{The needs for CLIL}

All the participants, teaching similar grades, expressed that they need more in-depth training about the philosophy and implementation of CLIL for themselves, as is demonstrated in the following excerpts:
The school had better provide the materials that the teachers need for CLIL classes and there might be a separate room with materials that the teachers might need when they are getting prepared for the CLIL classes... Participant 1

Teachers who are going to have CLIL lessons must have detailed information about it. There might be workshops or demo lessons (or microteaching) for this method. In this way, we can have an effective lesson with CLIL. Participant 4 In this regard, the majority of the participants also pointed out that CLIL education needs to be provided for subject teachers as well, as put in the excerpts below:

...subject teachers need to be informed about CLIL's facilities which help them teaching a foreign language effectively by using their subjects across the curriculum... Participant 2

I believe that social and experimental science teachers, art teachers and teachers of other sciences be informed and trained about CLIL to sustain long-lasting effects of our CLIL studies... Participant 1

\section{Challenges for the implementation of CLIL}

The participants also underlined the obstacles they have for implementing CLIL, some of which are teachers' lack of competence, time and materials, the negative attitude of subject teachers, and lack of motivation and ability of the students. Specifically, all of the participants said that English teachers do not have sufficient information about CLIL or they are not competent enough, while four of them referred to a likely negative attitude of the subject teachers, as displayed in the following excerpts:

... Also, as CLIL activities take too much time to be able to get prepared and to be able to deliver it precisely to do students, I always have some problems with catching the annual plan, the curriculum and the units to be covered on time... Participant 1

... sometimes, I have lots of difficulties finding the materials I need for CLIL classes...I usually have to spend from my budget, limiting me for sure. (other teachers have the same problem, too) ... Participant 1 
.... Another problem is the lack of materials to be used in the class which is a big problem, therefore, we teachers should improve our creativity to find the materials or produce.... which necessitates further knowledge and expertise in this field.. Participant 5

Other subject teachers might take, for example: 'Why doesn't the English teacher stick to teaching English and leave my subject to me?' (sometimes I have this problem, too). Participant 1

A subject teacher may think 'Teaching English is the problem of English teacher. So, leave my subject to me.' Participant 2

\section{Benefits of CLIL}

The other recurring theme in the essays is pertinent to the benefits of CLIL. In particular, all of the participants underlined that fact that CLIL enables contextualization of language learning by providing authentic settings, thus helping students acquire the language better, as is shown in the following excerpt: ...my students also cooperated with their classmates to do tasks and projects about the subject matter. As they needed to talk more, share more, collaborate more, search more, speak more and produce more, they had never felt like doing the things alone because they weren't learning the language or doing some parrot memorizing of the vocabulary in the box (honestly, most of the traditional main course books offer this kind of boring and spoon-feeding stuff) but a lot more than that, they were exploring, discovering, creating, searching, combining, communicating, connecting and CLILing...Participant 1

The other common pattern in the essays is that CLIL fosters and contributes to learners' motivation, creativity, collaboration and communication (fluency) as indicated in the following excerpts:

...CLIL is not a language class, it's a class about a subject that the students are very interested in, taught in a language which students are not familiar with. But in the process of learning about the subject, the students acquire linguistic competence, as well. CLIL class shoots many birds with one stone: the subject matter and the target language...Learning is improved through increased motivation and the study of natural language seen in context. When learners are interested in a topic, they are motivated to acquire language to communicate... Participant 3

...Secondly, fluency is more important than accuracy and errors are a natural part of language learning. Learners develop fluency in English by using English to communicate for a variety of purposes... Participant 3

... teaching English without using this method will lead us back to our old, boring way of teaching mostly, teaching grammar first and trying to move on to the content and the vocabulary. But with this method, if we start with the content, grammar just comes along automatically which is going to be more enjoyable and therefore students will be more likely to remember and use everything they have been taught, later on in their lives... Participant 5

...Reading texts are essential in CLIL. They present a context which helps to develop a new vocabulary. Attaching words to their surroundings works and that's the most remarkable, positive effect of CLIL... Participant 2

\section{Interviews}

To complement the results extracted from reflective essays and gain more comprehensive and in-depth data, the participants were individually interviewed with 7 questions. The interviews, semistructured in design, were held in a quiet room of the school and lasted 25-30 min. The interviews were arranged after the implementation of the CLIL-based lesson, and upon the consent of the participants, they were audiotaped and transcribed by the researchers. The detailed result of the interviews is as follows:

\section{Benefits of the CLIL-based lessons}

The participants were asked whether the students benefitted from the CLIL lesson they implemented recently. All the participants stated that the students gained many takeaways from the lesson, among which are content knowledge and developing communication skills, as shown in the excerpts below: 
Sure. I think they benefited a lot from CLIL. For instance, as language is a tool for communication in CLIL classes, they were not imprisoned in the grammar, rules, limited vocabulary, drills, patterns or exercises. They did not only tour around the core vocabulary or core language that the lesson offered but also they tried to get what the content already led them to... Participant 1

Yes, they did. The students informed me that they enjoyed learning about the petroleum and energy sources and the challenges. To me, it was amazing because the students were doing group work, filling each other in about the materials they studied and participating actively... Participant 5

Apart from these two of the participants pointed out that the students also developed their critical thinking and collaboration skills in this specific lesson.

Yes, they benefited a lot. They not only learned the content but they had the lesson which includes all the skills like speaking, listening, writing, reading. They developed their critical thinking; as well... Participant 3

They mostly enjoyed developing an action plan in groups at the end since the task required them to collaborate and produce... Participant 4

\section{The Advantages of CLIL-based Materials}

The participants were asked to describe any benefits of CLIL materials that they perceive from CLIL lessons. All of the participants said that the prepared materials helped students increase their vocabulary with the help of content, as is seen in the following excerpt:

The students focused on the topic and learned the target words through the content. Hence, they comprehended the reading text about petroleum and realized the words concerning it like lipstick, umbrella etc.... Participant 2

They also emphasized the effect of the materials on students' speaking abilities, as indicated in the following excerpt:

The lesson was closely related to real life by integrating authentic materials, which enabled students to use a foreign language in a real- life context. They were sort of forced to speak... Participant 1

\section{Contribution to Language Skills and Subject Knowledge}

The participants were asked about the potential contributions of CLIL in terms of language skills and subject knowledge. Their response to this question is centered on the fact that CLIL lessons reinforce four skills, as indicated in the excerpts below:

The lesson all included four skills so they read, spoke, listened and wrote something unconsciously while trying to do the process... Participant 3

I think CLIL is helpful to improve four language skills. Reading and comprehension come first because students deal with content-based material and they spend plenty of time to understand it. Reading is a major source for them. Speaking skills are also improved when the students know the fact that accuracy is more important than fluency. Thus they can express themselves comfortably. Listening is vital too because sometimes lessons are based on listening texts... Participant 2

\section{Challenges and Familiarity with Subject Knowledge}

The next question inquired about the challenges of the teachers during the implementation of CLIL and the necessity of subject knowledge for ELT teachers. For the former one, all of the participants expressed that if the content is not related to students' needs and interests, it causes trouble to grab their attention to the topic, as demonstrated in the coming excerpts: First of all, the content chosen for the lesson must be related to the students' needs. If it is not, students find it boring and they don't want to work on it... Participant 4

It took time to get their attention on the content because the content was far different from what we had been having for this month in our class. And. All my experience proved to me that if the content is exciting for them, it works well. The content must appropriate for their age group and their interest as well... Participant 3 
They also indicated that they need sufficient time to prepare for the lesson, as is evident in the following excerpt:

CLIL lessons naturally require more time to prepare in comparison to other regular lessons.

That's why we sometimes get in trouble to make perfect preparation due to the limited preparation time at the school...Participant 4

In concern with the familiarity with the subject knowledge, the participants have opposing ideas, in other words, three of the participants, as indicated below:

...you do not need to be an 'expert' in a particular subject or topic to be able to use them because CLIL is not specific to a certain field. How can we develop expertise in every science or field... Participant 1

It is a little challenging because even the teachers have to learn new stuff and study them for a while before they can teach them. For that reason, of course, we as teachers need to have that subject knowledge we're going to teach... Participant 3

\section{Requirements of CLIL}

When the participants were asked about the overall requirements of CLIL-based lessons, they mostly highlighted the necessity of time and effort for designing/preparing materials, collaborating with subject teachers, as is shown in the following excerpt:

I think CLIL requires a lot of time -especially if you are a beginner-. First of all, you need to learn before you teach (you are a teacher and a student at the same time); this requires time and extra effort. Secondly, as the teachers don't have some specific books or resources for their CLIL implementations in most institutions, they have to find, organize and create their materials by themselves. Furthermore, implementations take too much time even it pays off in the end, considering the students' progress and outcomes... Participant 1

If we are to teach something not related to our field e.g. Science, we have to collaborate with subject teachers and get a lot of insight into the topic. So, teachers who include CLIL in their lessons should be willing and ready to put a great deal of effort....Participant 5

\section{Needs of CLIL}

The participants were lastly asked about the needs of CLIL in their institution considering their experience. The responses to these questions indicated that all of them think that CLIL should be integrated into the ELT curriculum. They also recommend that school administration provide necessary conditions, namely materials, training, the community of practices, schedule and so forth for the implementation of CLIL. The following excerpts show the proof of this result:

The materials that the teachers might need for their CLIL classes should be listed again by the teachers at the beginning of the year and they should be provided before the school year starts... There could be a library or a book corner where there are some CLIL resources, examples and implementations for the teachers to get inspired by the things that people have already tried and benefited from....Participant 1

CLIL will be successful if teachers are given enough opportunities for learning and experimenting. The curriculum is the biggest handicap because we are expected to teach topics in a certain period with certain materials. Trying to implement CLIL in this process can be overwhelming, intimidating and confusing... Participant 2

In our institution, we need a curriculum based on CLIL first of all. All the teachers should inspire and encourage one another. They should provide help whenever needed. Finally, we need materials that can make CLIL more applicable... Participant 5

A comparative analysis of the findings obtained from both the reflective essays and the interviews indicated that teachers had overlapping and positive attitudes towards the implementation of CLIL in their classrooms. The participants mostly agreed that CLIL-based lessons helped students contextualize language learning by providing authentic settings, fostered and contributed to students' motivation, creativity, collaboration and communication 
(especially fluency); increased students' subject and vocabulary knowledge; reinforced four skills and developed critical thinking skills. However, the participant teachers agreed that the implementation of CLIL brought some challenges along. The most frequently referred challenge was the fact that implementation of CLIL required quite a lot of time, specifically, time to get familiar with the content i.e. subject knowledge; time to find or develop materials; time to collaborate with subject teachers, some of whom had negative attitudes toward language teachers as they perceived this as an intervention into their field and time to integrate it into their busy annual plans. Another common obstacle stated by the participants stemmed.

\section{Discussion}

The present study aimed to investigate Turkish EFL teachers' attitudes, perceptions and needs of CLIL. In an attempt to do so, the study was mainly concerned with understanding and projecting teachers' viewpoints for future reference. In line with this goal, answers to the research questions "What are the teachers' perceptions about implementing CLIL-based approach in their classroom practices?" and "What are the teachers' needs for developing and implementing CLIL-based lessons in their classes?" were sought. Such being the case, teachers were provided with an article to get them familiarized with the concept of CLIL or improving their insight about CLIL and its effects and asked to write reflective essays. After that, they were asked to implement a CLIL-based lesson plan and interviewed afterward. Careful analysis of the findings and scrutiny of the data obtained from the aforementioned materials revealed that teachers perceived several needs, challenges, and benefits when it comes to implementing CLIL in their classrooms.

As the researchers embarked on to examine the participating teachers' perceptions, attitudes and needs of CLIL, it can be concluded that they all have positive attitudes towards CLIL-based lessons and this is also congruent with the previously conducted studies in the literature. Defouz et al. (2007), for example, yielded similar results to the present study claiming that teachers, even though before the implementation phase of the study they had a negative attitude to CLIL, a change towards positivity took place in their demeanor afterward. However, CLIL brings some challenges, such as teachers' lack of competence, the negative attitude of subject teachers, lack of motivation and ability of students. Specifically, it can be argued that teachers should undergo training programs pertinent to CLIL implementations in EFL classrooms and these programs had better meet, if none, teachers' needs in terms of what they deal with in their contexts given that it is the students whose interests and needs are of utmost importance. If neglected, this might, inevitably, result in a negative paradigm shift where a considerable amount of time and effort would go into hollow promises. Simply put, the issue of applying CLIL-based lessons in classrooms in a way that things are in apple-pie order is a matter that needs to be taken into consideration meticulously.

As for possibly successful integration of CLIL into ELT curricula, there are some preliminary steps to be taken, the first of which happens to be training that might, preferably, be based on their needs, viz., for teachers to have more insight into the issue. It has also been suggested by the participating teachers that such training provides support and advice tailored to their particular teaching context, which concurs with previous studies existent in the literature (Infante et al., 2009 \& Wolff, 2012). In parallel to this, the participants also pointed out that materials play a key role in succeeding in CLIL-based lessons; therefore, it would be rather kafkaesque to turn a blind eye to the fact that teachers should be familiarized with the relevant materials that will help them make the best out of what they are inclined to do in their settings. One way to do so is to seek out answers to questions that teachers might have concerning the issue above by conducting NAs, which is also in line with the existing literature. As Ruiz-Garrido and Fortanet-Gomez (2009) claimed, to discover the needs of students and teachers regarding the CLIL implementation in EFL/ESL classes, NAs should be conducted to organize the required arrangements. Moreover, Mehisto (2010) pointed out there should be set and ready-to-use criteria to develop better CLILrelated materials, which lays a particular emphasis on the necessity of having language practitioners be acquainted with the knowledge requisite for a 
successful CLIL integration. The participants also expressed a need for more time and resources such as hand-outs and materials to be used for future reference and classroom use. Therefore, technical and technological infrastructure should be provided by government authorities to meet this need.

Yet again, it would not be very wise to gloss over the fact that the present study is limited in its scope as it focused mainly on the subjects' value regarding the CLIL-based lessons but not include classroom observations of actual practices in the study. This limitation should be considered in future studies. That said, studies to come along would include classroom observations to better analyze and interpret the findings and offer more concrete suggestions regarding the issue. Another limitation of the study is that the researchers and the participant's teachers prepared the CLIL-based lesson plan used in the study together due to the participants' heavy workload since the end of the term was imminent. It would have been much better if the lessons were planned by the participants themselves, which would have reflected their insights and understanding of CLIL more precisely. As such, the findings of the present study might as well be replicated with larger samples consisting of more participants within similar and different contexts and variables. Even though there is confidence in the emergent findings of this study because they replicate similar projects in other settings around the globe, much research is deemed to be necessary to investigate the issue in more depth.

\section{Conclusion}

This study targeted at identifying the needs of CLIL lecturers along with their perceptions. In so doing, L2 teachers with diverse CLIL experience got the opportunity to deliver CLIL instruction. All in all, the present study seemed to have achieved its aim to unearth the perceptions and needs of EFL science high school teachers doing CLIL in their contexts. In this respect, the results indicated that even though they, being aware and convinced about the advantages of CLIL, are keen to integrate CLIL, the participant teachers in the science high school encounter challenges. The school administration thus ought to take the result of this research into serious consideration so that the teaching staff is provided necessary requisites, skills, training, flexibilities and conditions. Lecturers' concerns regarding effective CLIL delivery was also revealed since they reported their suspicions as to whether they were efficient in lesson plans and practice.

Since these are EFL teachers with little background in CLIL, we need to address it in inservice and pre-service teacher education programs in which teachers get acquainted and excelled at CLIL methodology.

\section{References}

Arslan, Recep Şahin, and Cengiz Koray Saka. "Teaching English to Science Students Via Theme-Based Model of Content-Based Instruction." Journal of Turkish Science Education, vol. 7, no. 4, 2010, pp. 26-36.

Banegas, Dario Luis. "Content and Language Integrated Learning in Argentina 20082011." Latin American Journal of Content and Language Integrated Learning, vol. 4, no. 2, 2011, pp. 33-50.

Bedir, H. "The Perceptions of ELT Prospective Teachers on CLIL." Conference on Modernizing Educational Perspectives in Content and Language Integrated Learning, 2013.

Bozdoğan, Derya, and Buket Karlıdağ. "A Case of CLIL Practice in Turkish Context: Lending an ear to Students." Asian EFL Journal, vol. 15, no. 4, 2013, pp. 90-111.

Canbay, Mehmet Orkun. Strengthening a ContentBased Instruction Curriculum by a Needs Analysis, Bilkent University, 2006.

Marsh, David, and Dieter Wolff. Diverse Contexts Converging Goals, Peter Lang, 2007.

De Graaff, Rick, et al. "Identifying Effective L2 Pedagogy in Content and Language Integrated Learning (CLIL)." CLIL Special issue, vol. 16, no. 3, 2007, pp. 12-19.

Flick, Uwe. An Introduction to Qualitative Research, Sage Publications, 2009.

Infante, Debora, et al. "The Effects of CLIL from the Perspective of Experienced Teachers." CLIL Practice: Perspectives from the Field, edited by David Marsh, et al., University of Jyväskylä, 2009, pp.156-163. 
Kiraz, Aúkõn, et al. "Effect of Science and Technology Learning with Foreign Language on the Attitude and Success of Students." Procedia Social and Behavioral Sciences, vol. 2, 2010, pp. 4130-4136.

Kızıltan, Nalân, and Ceylan Yangın Ersanlı. "The Contributions of Theme-based CBI to Turkish Young Learners' Language Development in English." Journal of Language and Linguistic Studies, vol. 3, no. 1, 2007.

Mehisto, Peter. "Criteria for Producing CLIL Learning Material.”Encuentro, vol. 21, 2012, pp. 15-33.

Miles, Matthew B., and A. Michael Huberman. Qualitative Data Analysis, Sage Publications, 1994.

Nikula, Tarja. "CLIL Classroom Discourse: Research from Europe." Journal of Immersion and Content-Based Language Education, vol. 1, no. 1, 2013, pp. 70-100.

Oruç, N. "English-Medium Instruction: Does It Work?" Ç. ̈. Sosyal Bilimler Enstitüsü Dergisi, vol. 17, no. 1, 2008, pp. 345-356.

Patton, Michael Quinn. How to Use Qualitative Methods in Evaluation, Sage Publications, 1987.

\section{Author Details}

Ahmet Cihat Yavuz, School of Foreign Languages, Bursa Technical University, Bursa, Turkey,

Email ID: ahmetcihatyavuz@gmail.com

Ali Öztüfekçi, Department of ELT, Bahçeşehir University, Istanbul, Turkey, Email ID: oztufekci.a@gmail.com

Aybüke Demet Ören, State High School, Istanbul, Turkey, Email ID: kaplan-ayten@hotmail.com

Ayten Kaplan, Vocational High School, Istanbul, Turkey, Email ID: ademetoren@gmail.com

Çiğdem Yilmaz Uzunkaya, Sehir University, Istanbul, Turkey, Email ID: y.cigdem@hotmail.com 